\title{
Conhecendo a maioria: o perfil sociodemográfico dos brasileiros que empreendem em condições de pobreza
}

\author{
Daniel Do Prado Pagotto ${ }^{1}$ \\ Cândido Vieira Borges Junior² \\ Gabriel Borges Silva ${ }^{3}$ \\ Daiane Martins Teixeira ${ }^{4}$
}

\footnotetext{
${ }^{1}$ Laboratório de Pesquisa em Empreendedorismo e Inovação (LAPEI-UFG) / Programa de Pós-Graduação em Administração / Universidade Federal de Goiás / Centro Universitário do Distrito Federal (UDF)

2 Programa de Pós-Graduação em Administração (PPGADM) / Universidade Federal de Goiás

${ }^{3}$ Laboratório de Pesquisa em Empreendedorismo e Inovação (LAPEI-UFG) / Universidade Federal de Goiás

${ }^{4}$ Laboratório de Pesquisa em Empreendedorismo e Inovação (LAPEI-UFG) / Programa de Pós-Graduação em Administração / Universidade Federal de Goiás
} 


\section{brasileiros que empreendem em condições de pobreza}

Resumo: A presente pesquisa tem como objetivo traçar o perfil sociodemográfico de empreendedores em condição de pobreza. Para isso, o estudo foi conduzido a partir de dados secundários do CADÚNICO $(\mathrm{N}=2177582)$. Os resultados permitiram observar que um dos perfis de empreendedores, o trabalhador por conta própria, possui desvantagem em termos de renda, escolaridade e acesso a condições básicas de moradia. Esse estudo contribui para lançar um olhar mais aprofundado para este grupo de empreendedores que, mesmo sendo uma parcela significativa da população, é negligenciado pela academia e por políticas públicas mais aderentes à realidade deles.

Palavras-chave: empreendedorismo e pobreza; trabalho por conta própria; cadastro único

\section{Introdução}

O trabalho por conta própria é um fenômeno de presença significativa na sociedade brasileira. Segundo dados do IBGE, em julho de 2019, 24,1 milhões de brasileiros estavam nessa situação (IBGE, 2019). Este contexto não é exclusivo do Brasil. Ele existe em qualquer país, mas é nos países em desenvolvimento que sua presença é maior (FIELDS, 2019). Na África Subsaariana, por exemplo, 55,6\% da população economicamente ativa atua como trabalhador por conta própria. Em contrapartida, em localizações mais desenvolvidas, como a Europa, representam taxas de 10,2\% da população economicamente ativa (GINDLING; NEWHOUSE, 2014).

No campo do empreendedorismo não há consenso se o trabalho por conta própria é ou não uma forma de empreendedorismo. De um lado, existem aqueles que consideram o trabalho por conta própria não pode ser considerado empreendedorismo. Estes autores defendem que o trabalho por conta própria são em geral, negócios informais, pouco inovadores, sem potencial de crescimento, de baixo impacto e que agregam pouco valor ao desenvolvimento econômico e social (FIELDS, 2019; PLOTNIKOVA; ROMERO; MARTI, 2016).

Por outro lado, existem autores que defendem que o trabalho por conta própria é uma forma de empreendedorismo. Pesquisadores argumentam que independente do nível de inovação proposto, é uma atividade econômica onde os indivíduos desenvolvem um processo empreendedor para a criação de um negócio que gera impacto para o indivíduo e para a sociedade (MORRIS; NEUMEYER; KURATKO, 2015). O estudo do Global Entrepreneurship Monitor (GEM), por exemplo, considera este tipo de atividade como sendo uma forma de empreendedorismo e geralmente está associada a um empreendedorismo por necessidade (NAUDÉ, 2010). Dentre a tipologia proposta por Morris, Neumeye e Kuratko (2015) o trabalho por conta própria é o empreendedorismo de sobrevivência. $O$ presente artigo se alinha com a segunda perspectiva e considera o trabalho por conta própria como um tipo de empreendedorismo.

Este tipo de empreendedorismo é ainda mais presente entre as pessoas de baixa renda ou em situação de pobreza (HOLZMANN, 2013). Pela falta de outras possibilidades de trabalho ou geração de renda, os indivíduos optam por tentar garantir ou complementar a subsistência por meio do trabalho por conta própria (TAMVADA, 2010). Pelas condições econômicas em que vivem e pelos recursos que dispõem, praticamente inexistem negócios inovadores de alto impacto empreendidos por pessoas em condições de pobreza (HOLZMANN, 2013). Ainda assim, estes negócios geram renda para os empreendedores, atendem parte das necessidades locais por bens e serviços e, em alguns casos, se desenvolvem gerando empregos e alcançando o crescimento (MORRIS: NEUMEYER: KURATKO. 2015). 
pobreza é caracterizado por ser uma área de estudo que carece de investigações dentro no contexto das pesquisas em administração (CUMMING; JOHAN; UZUEGBUNAM, 2019). Isso se deve, em certa medida, por ser um campo de investigação fragmentado entre várias perspectivas e domínios teóricos, o que resulta em um baixo número de publicações, porém, crescente (SUTTER; BRUTON; CHEN, 2018). Para o bom desenvolvimento de políticas públicas e instrumentos de apoio específicos para o empreendedorismo desenvolvido neste contexto, é necessário compreender as especificidades deste tipo de empreendedorismo, inclusive o perfil dos empreendedores. O objetivo da pesquisa é, desta forma, responder a seguinte questão: qual é o perfil do sociodemográfico do empreendedor em condição de pobreza no Brasil?

Alguns estudos já investigaram o fenômeno do trabalho por conta própria por exemplo, Holzmann (2013) e Santiago e Vasconcelos (2017). Estas pesquisas aportaram conhecimentos sobre o perfil destes trabalhadores no Brasil. O presente artigo avança nos conhecimentos sobre o tema, ao focar a análise apenas nos trabalhadores por conta própria que estão em condições de pobreza e por abranger uma outra forma de empreendedor também presente nestas condições - o de empregador. Trata-se de pessoas que ainda que tenham negócios informais e vivem em condições de pobreza já conseguem empregar pessoas e por esta condição são considerados em uma categoria diferente do trabalhador por contra própria. Eles são chamados de empregadores pelos institutos de estatísticas oficiais (IBGE, 2019) e pela literatura especializada (GINDLING; NEWHOUSE, 2014; MANDELMAN; MONTES-ROJAS, 2009). Ao considerar trabalhadores por conta própria e empregadores, o artigo abrange, desta forma todas as expressões de empreendedorismo de negócio em condições de pobreza.

Este estudo possui contribuições práticas e acadêmicas. Sob a primeira perspectiva, a pesquisa traz um retrato do empreendedor em condição de pobreza no Brasil, chamando a atenção para a realidade de uma parcela significativa da população. A produção de conhecimento sobre o tema é uma ação que pode contribuir para a formulação de políticas públicas para o empreendedorismo na camada de baixa renda (SMITH et al., 2019).

Sob a perspectiva teórica, é um avanço para cristalização de um corpo de conhecimento relativamente novo ao campo de empreendedorismo, que é o empreendedorismo em condições de pobreza. Sob a perspectiva metodológica, esse trabalho contribui ao difundir o uso de uma base de dados secundários com grande potencial para a pesquisa em empreendedorismo em condições de pobreza - o CADUNICO. Trata-se de uma base que reúne informações sobre aproximadamente 14 milhões de brasileiros que vivem em condições de pobreza e acessas aos programas sociais do governo federal.

\section{Fundamentação teórica}

De acordo com dados do Banco Mundial (2018), o mundo possui 10\% da sua população vivendo abaixo da linha da pobreza. No Brasil, este número exige atenção especialmente diante do aumento de $0,8 \%$ em relação à última medição, em 2016, totalizando um contingente de 55 milhões de pessoas vivendo abaixo da linha da pobreza em 2017 (IBGE, 2018). Vale ressaltar que os dados do Banco Mundial utilizam como referência o valor de US $\$ 1,90$ por pessoa ao dia. O Brasil, por ser um país de renda médiaalta, utiliza como referência o valor de US $\$ 5,50$ por pessoa ao dia.

Um dos possíveis caminhos apontados para as pessoas que vivem nestas condições, é o empreendedorismo, que aparece como mecanismo capaz de melhorar as condições de renda dos indivíduos e reduzir as taxas de pobreza de regiões e países. (BRUTON; KETCHEN; IRELAND, 2013). Apesar de avanços significativos nas

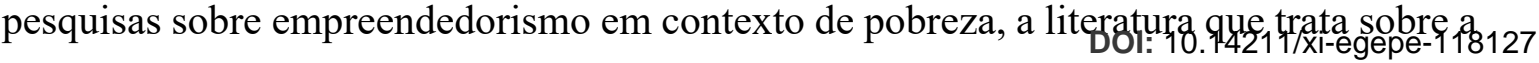


com certo distanciamento entre a teoria e a prática (SMITH et al., 2019; SUTTER; BRUTON; CHEN, 2018).

Esse último ponto acontece, em certa medida, devido à compreensão limitada que se tem sobre o empreendedorismo em condições de pobreza. Muitas vezes, busca-se aplicar, sem nenhum tipo de adaptação, conceitos vinculados à noção do empreendedorismo inovador, baseado na lógica schumpeteriana, a contextos onde indivíduos possuem muitas barreiras e restrições devido à condição socioeconômica (BRUTON; KETCHEN; IRELAND, 2013; SLADE; ZIETSMA, 2018).

$\mathrm{Na}$ conjuntura de países em desenvolvimento, um ator que emerge como agente empreendedor é o trabalhador por conta própria. Essa forma de trabalho é uma alternativa para indivíduos fugirem de dificuldades financeiras devido à falta de oportunidades de trabalho (KRASNIQI, 2014). Em complemento, George et al., (2016) argumenta que pessoas em condições de pobreza são impulsionadas ao trabalho independente exatamente por ser um caminho que garante a sobrevivência.

Empreendimentos desta categoria são marcados por objetivo associado a simples subsistência do indivíduo. Geralmente possuem poucos recursos e carecem de relações institucionais, como em bancos. Transações financeiras ocorrem por meio de dinheiro ou trocas, a preços sensíveis a um mercado competitivo composto por produtos com baixa taxa de diferenciação. Como o maior foco do negócio reside sobre o suprimento de renda para os empreendedores, uma vez que os custos são pagos não há ações voltadas para o reinvestimento e crescimento (MORRIS; NEUMEYER; KURATKO, 2015).

Trabalhadores por conta própria, especialmente em países em desenvolvimento, são marcados por condições de desvantagem, carecem de proteções trabalhistas e registram rendimentos menores que os empregados assalariados. Tais condições inviabilizam que esses empreendedores sejam propulsores de inovação e crescimento econômico (BARROS; PEREIRA, 2008; HOLZMANN, 2013; VIVARELLI, 2013), havendo, inclusive, evidências de que os esforços empreendedores nesse contexto não resultam em nenhum retorno sobre à melhoria na distribuição de renda ou mesmo redução de pobreza (BECK; DEMIRGUC-KUNT; LEVINE, 2005; KOROSTELEVA; STĘPIEŃ-BAIG, 2019; YANYA; ABDUL-HAKIM; ABDULRAZAK, 2013). No entanto, argumentos contrários sugerem que trabalhadores por conta própria conseguem converter recursos não produtivos em produtivos. Além disso, o aprendizado adquirido ao longo do processo empreendedor contribuiria para a criação de empreendimentos mais qualificados e competitivos no futuro (MORRIS; NEUMEYER; KURATKO, 2015).

No Brasil, de acordo com dados da PNAD de 2014, levantados por Santiago e Vasconcelos (2017), o percentual de trabalhadores por conta própria era de aproximadamente $21,3 \%$ da população economicamente ativa, enquanto empregados (com carteira, sem carteira, servidores público e trabalhadores domésticos) correspondiam a $61 \%$ da amostra.

Um estudo utilizando dados da Índia entre julho de 2011 e junho de 2012, com uma amostra de 456.999 pessoas, em que 134.665 representavam trabalhadores, mostrou que a maioria se enquadrava em trabalhadores por conta própria, com $40 \%$, enquanto $1 \%$ eram empregadores. Já empregados regulares eram $23 \%$ da amostra (SARKAR; RUFÍN; HAUGHTON, 2018).

A partir de dados da PNAD, Holzmann (2013) alerta sobre a desvantagem do trabalhador por conta própria em termos de rendimento. Usando dados entre 2004 e 2011 , a autora constatou que a cada ano, o rendimento médio mensal do trabalhador assalariado sempre foi maior do que o do trabalhador por conta própria. Calculando uma média anual

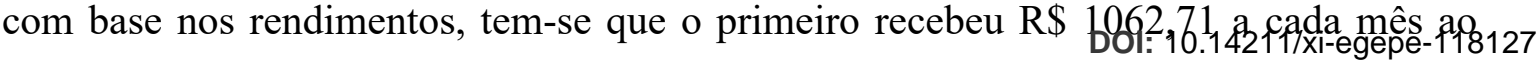


$\mathrm{R} \$ 932,57$.

Esses resultados não são particularidades do Brasil, uma vez que estudos comparativos internacionais apontam para o mesmo comportamento (GINDLING; NEWHOUSE, 2014). Em pesquisa realizada na Índia, constatou-se que os gastos com consumo per capita é maior entre assalariados em relação a trabalhadores por conta própria (TAMVADA, 2010). Na Argentina, de modo semelhante, os rendimentos de trabalhadores por conta própria foram inferiores ao dos trabalhadores assalariados (MANDELMAN; MONTES-ROJAS, 2009).

Além da questão da renda, sabe-se que trabalhadores por conta própria possuem restrições no acesso a direitos, como, por exemplo, a filiação à previdência social. Constatou-se que $84,4 \%$ dos trabalhadores por conta própria não contribuíam à previdência social. Número este ainda mais alarmante nas camadas mais pobres, onde o percentual de não contribuintes chega a $97,7 \%$ para trabalhadores que recebem até meio salário mínimo (HOLZMANN, 2013). Essa questão pode ser explicada, em partes, pela alta quantidade de pessoas em condição de informalidade: $60,6 \%$ dos trabalhadores por conta própria estão nessa situação (SANTIAGO; VASCONCELOS, 2017).

Sobre outras variáveis socioeconômicas, o trabalhador por conta própria no Brasil foi majoritariamente masculino (64,1\%), de cor branca $(45,5 \%)$, seguidamente de parda (44,1\%). A faixa de idade predominante foi de 40 a 44 anos $(16,8 \%)$. Por fim, em relação à escolaridade, observou-se maior proporção de indivíduos com 4 a 7 anos de estudo, o que corresponde ao ensino fundamental completo. Logo em sequência houve os trabalhadores com anos de estudo entre 11 e 14 anos e, por fim, 8 a 10 (SANTIAGO; VASCONCELOS, 2017).

\section{Método}

A presente pesquisa caracteriza-se como exploratória, quantitativa, com corte transversal e uso de dados secundários. Estes tiveram origem na base de dados do Cadastro Único. O Cadastro Único é regulamentado pelo Decreto $n^{\circ} 6.135$, de 26 de junho de 2007 e constitui a porta de entrada de cidadãos em vulnerabilidade social para concessão de benefícios dos Programas Sociais do Governo Federal, como: Programa Bolsa Família, Tarifa Social de Energia Elétrica, Programa Minha Casa Minha Vida, Bolsa Verde, entre outros (BRASIL, 2007).

O Cadastro Único constitui em um instrumento de identificação e categorização de famílias de baixa renda, registrando informações socioeconômicas que serão desmembradas no decorrer do texto, possibilitando que o governo tenha ciência da realidade da população, sendo a manutenção de responsabilidade compartilhada entre o governo federal, por intermédio do Ministério da Cidadania, os estados, os municípios e o Distrito Federal e, por agente operador do sistema, apresenta-se a Caixa Econômica Federal.

O processo de inscrição no Cadastro Único ocorre mediante uma busca ativa por parte do poder público municipal. São elegíveis à inscrição famílias, inclusive unipessoais, que se enquadrem nas seguintes regras:

- renda mensal familiar de até meio salário mínimo por pessoa;

- renda mensal familiar total de até três salários mínimos; ou

- renda familiar maior que três salários mínimos, desde que o cadastramento esteja vinculado à inclusão em programas sociais nas três esferas do governo;

- pessoas marginalizadas em situação de rua.

Após o preenchimento dos requisitos, o responsável pela unidade familiar

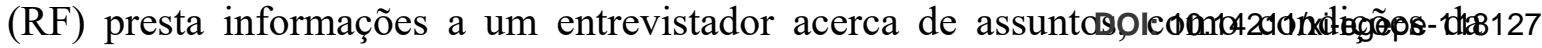


dentre outros. Todavia, apesar desse volume de dados, cabe ressaltar que apenas um conjunto de 64 variáveis encontra-se disponível para livre acesso no site do Ministério da Cidadania.

O referido ministério reúne dados de 2012 a 2017. Para esse estudo, utilizouse como referência a base disponível no último ano, que contou com um total de 14.548.324 de observações para pessoas e 5.130.647 para famílias. Por meio do software RStudio, os casos omissos foram tratados por meio do critério listwise de exclusão. Existem duas categorias de profissões que se enquadram como o empreendedor: o trabalhador por conta própria (bico, autônomo) e o empregador. Após o tratamento de casos omissos e outliers, a amostra foi composta por 2.429 .363 casos. Para fins de análises e comparações, os dados utilizados neste estudo se restringiram aos casos de trabalhadores por conta própria, empregador, empregados com carteira e empregados sem carteira. Com isso, a amostra final usada para esse estudo foi composta por 2.177.582 observações de pessoas e permitirá comparar empreendedores (trabalhadores por conta própria, empregadores) com duas modalidades de empregados (com e sem carteira).

\section{Resultados e Discussão}

A seguir serão trazidos resultados da análise de dados de natureza descritiva. Diante dos perfis da pesquisa, observa-se que o grupo majoritário dos perfis analisados constitui o trabalhador por conta própria, com 1488083 indivíduos (68,34\%). Em seguida, por volta de um terço do trabalhador por conta própria, apresenta-se o trabalhador com carteira com 532687 (24,46\%). O trabalhador sem carteira, em seguida, apresenta 155607 indivíduos $(7,15 \%)$. E, por último, conforme a tabela 1 , a menor parcela compreende $\mathrm{o}$ empregador com 1205 indivíduos e $0,06 \%$ da amostra.

Tabela 1 - Distribuição do perfil de trabalho

\begin{tabular}{|l|l|l|}
\hline Perfil de trabalho & Total & Percentual \\
\hline Trabalhador por conta própria & 1488083 & $68,34 \%$ \\
\hline Empregador & 1205 & $0,06 \%$ \\
\hline Trabalhador com carteira & 532687 & $24,46 \%$ \\
\hline Trabalhador sem carteira & 155607 & $7,15 \%$ \\
\hline
\end{tabular}

Observa-se uma predominância de trabalhadores por conta própria entre indivíduos em condições de pobreza. Estes resultados são divergentes com os dados da PNAD levantados por Santiago e Vasconcelos (2017), pois estes não realizam nenhum recorte sobre o perfil sociodemográfico. No entanto, existe convergência quando se trata de um estudo realizado na Índia, onde se registrou uma predominância de trabalhadores por conta própria no contexto de pobreza (SARKAR; RUFÍN; HAUGHTON, 2018).

Em relação à distribuição do sexo dos respondentes, percebe-se pela figura 2 que o sexo feminino foi predominante nos grupos da pesquisa, com exceção dos empregadores. Na maior parte das pesquisas, trabalhadores por conta própria são caracterizados por serem majoritariamente do sexo masculino (MANDELMAN; MONTES-ROJAS, 2009; SANTIAGO; VASCONCELOS, 2017). Todavia, sabe-se que este resultado pode ter sido ocasionado por um viés da própria base do CADÚNICO, uma vez que existe um estímulo que alguns dos benefícios elegíveis a partir do cadastro único sejam concedidos prioritariamente a mulheres. 


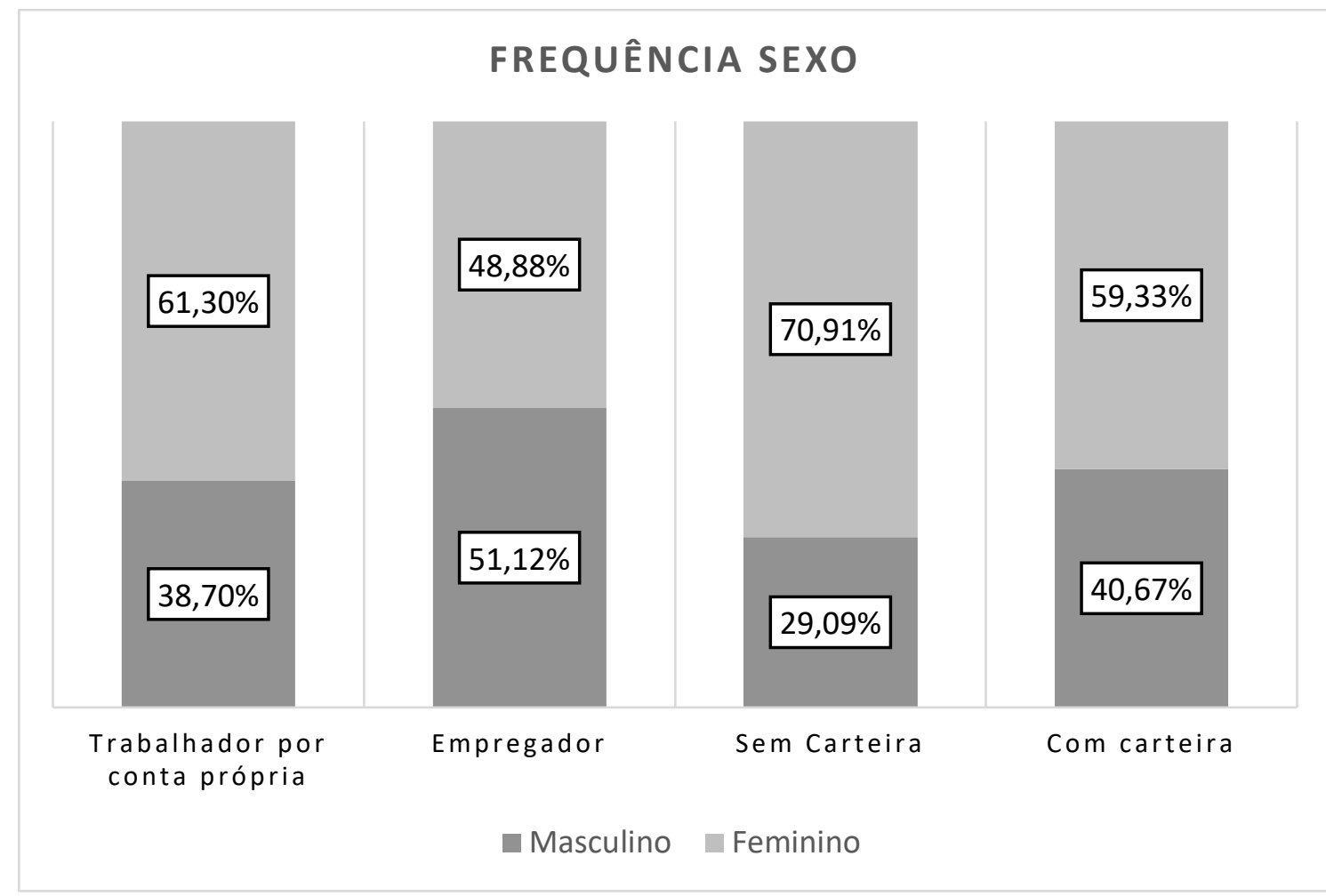

Fonte: elaborado pelos autores

Em termos de idade média desses grupos, percebe-se baixa variação entre os perfis de trabalho, conforme a figura 2. Moreira (2013) expõe dados similares com o resultado obtido, tendo em vista que a média de idade do empreendedor apresenta maior frequência nas faixas etárias de 25 e 39 anos e acima dos 40 anos. De modo análogo, Santiago e Vasconcelos (2017) evidenciam que a maior frequência aparece entre 35 e 49 anos.

Figura 2 - idade média

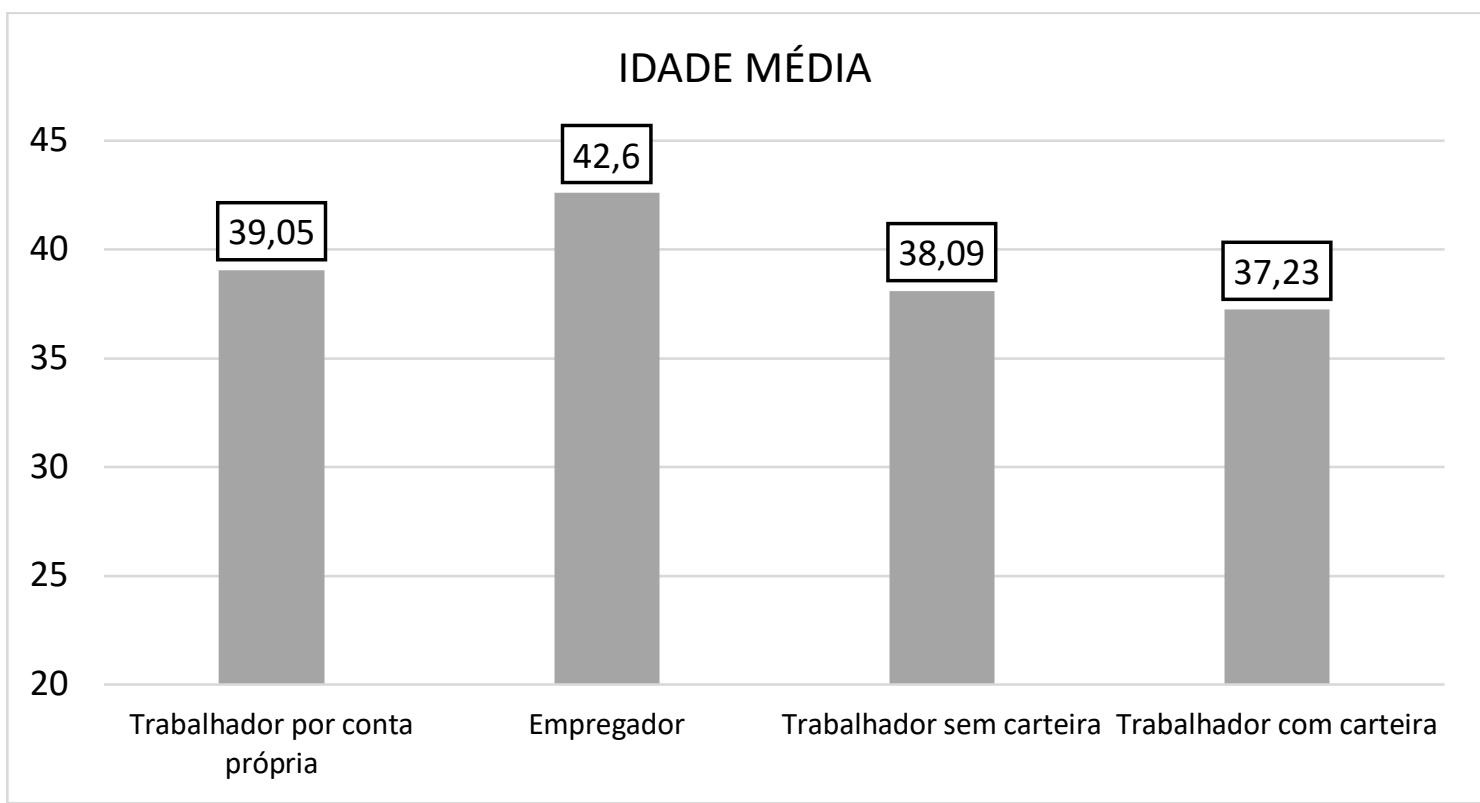

Fonte: elaborado pelos autores. 
Enquanto o trabalhador com carteira assinada recebe o maior valor, o trabalhador por conta própria é quem possui menor renda mensal. Diversos estudos já têm confirmado esse resultado, tanto no Brasil (HOLZMANN, 2013; SANTIAGO; VASCONCELOS, 2017), como também no exterior (MANDELMAN; MONTES-ROJAS, 2009).

Figura 3 - Renda mensal média

\section{RENDA MENSAL}

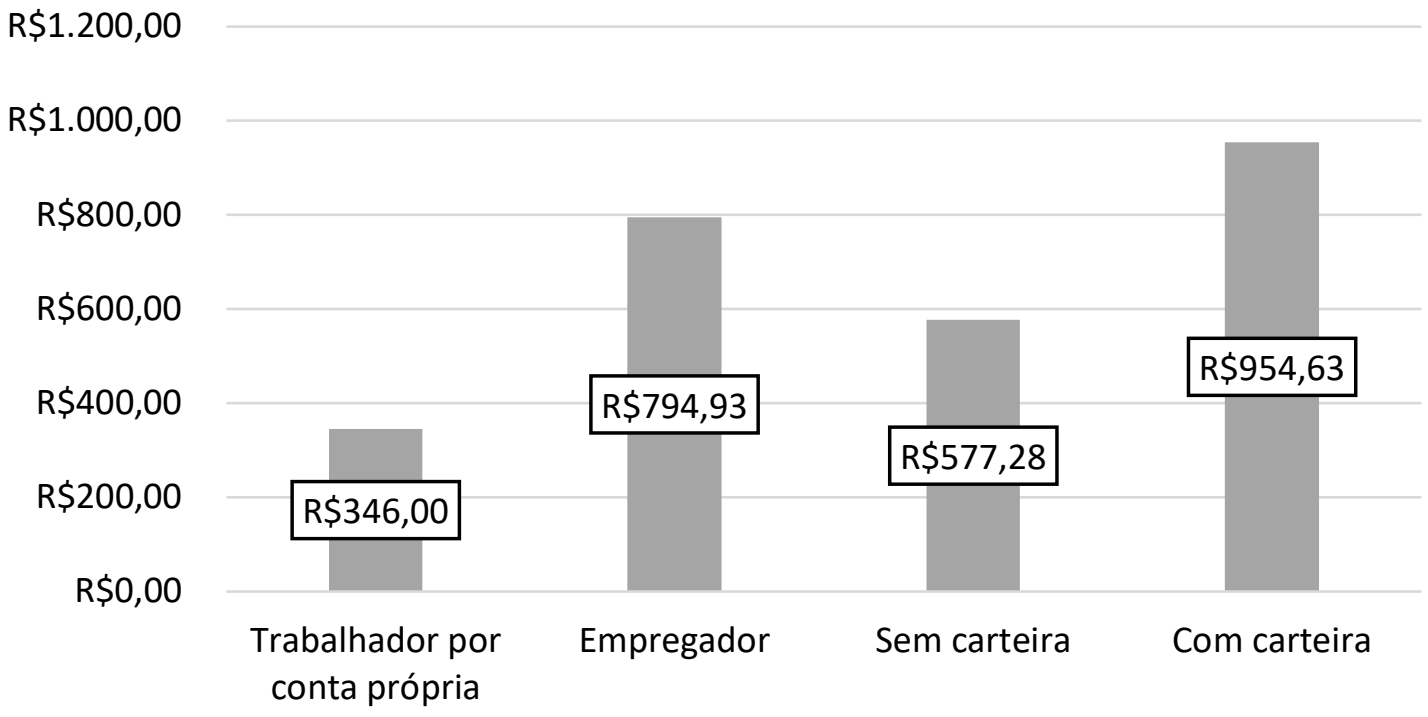

Fonte: elaborado pelos autores

Exclui-se dessa renda os valores recebidos pelo Programa Bolsa Família. Dos grupos analisados, os trabalhadores por conta própria são os que, proporcionalmente, recebem mais o benefício do governo (64,68\%). Em contrapartida, o grupo dos assalariados é o que possui menos registros no programa $(12,62 \%)$.

Figura 4 - Beneficiários do Programa Bolsa Família

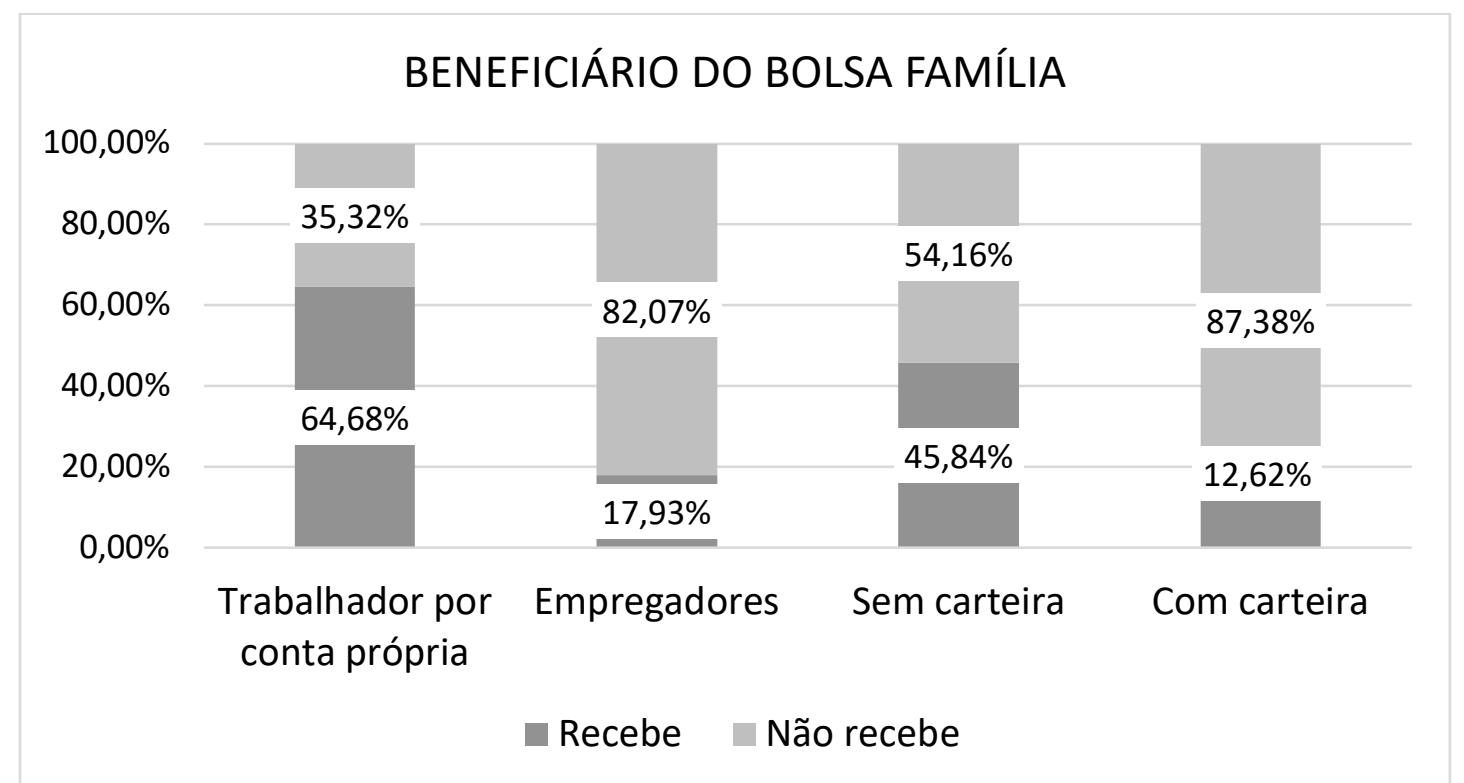


privação do atendimento a necessidades básicas (ROCHA, 2000; SEM, 2018), a seguir serão apresentados resultados exploratórios acerca de questões que envolvem a educação e condições de moradia.

Em relação ao grau de escolaridade, observa-se que, em todos os casos, os níveis mais recorrentes foram ensino médio, ensino fundamental 2, ensino fundamental 1, respectivamente. Houve baixa variação em relação às frequências de cada grupo, havendo apenas alguns casos sobressalentes, como a escolaridade do empregador no ensino superior, cuja proporção corresponde a seis vezes mais que a do trabalhador por conta própria, por exemplo.

Tabela 2 - Grau de escolaridade

\begin{tabular}{|c|c|c|c|c|}
\hline $\begin{array}{c}\text { Curso mais elevado que } \\
\text { frequentou }\end{array}$ & $\begin{array}{c}\text { Trabalhador por } \\
\text { conta própria }\end{array}$ & Empregador & $\begin{array}{c}\text { Sem } \\
\text { Carteira }\end{array}$ & Com Carteira \\
\hline $\begin{array}{c}\text { Ensino médio } 2^{\text {o }} \text { grau } \\
\begin{array}{c}\text { Ensino Fundamental 5 a } 8^{\mathrm{a}} \\
\text { séries }\end{array}\end{array}$ & $37,74 \%$ & $45,89 \%$ & $41,44 \%$ & $52,37 \%$ \\
\hline $\begin{array}{c}\text { Ensino Fundamental 1 } 1^{\mathrm{a}} \text { a } 4^{\mathrm{a}} \\
\text { séries }\end{array}$ & $23,26 \%$ & $24,40 \%$ & $28,61 \%$ & $24,91 \%$ \\
\hline Ensino Fundamental 9 anos & $3,65 \%$ & $2,32 \%$ & $3,45 \%$ & $2,32 \%$ \\
\hline $\begin{array}{c}\text { Superior, Aperfeiçoamento, } \\
\text { Mestrado, Doutorado }\end{array}$ & $1,10 \%$ & $6,80 \%$ & $3,24 \%$ & $2,81 \%$ \\
\hline Outros & $2,92 \%$ & $2,90 \%$ & $2,90 \%$ & $2,54 \%$ \\
\hline
\end{tabular}

Fonte: elaborado pelos autores.

Além destas questões, buscou-se compreender as condições da infraestrutura habitacional desses grupos. Primeiramente, a maioria, em média, possui coleta de lixo feita de modo direto. A outra parcela é composta por formas rudimentares de descarte do lixo, que incluem a prática de queimar os resíduos, jogar em terreno baldio ou em rio, lago ou mar.

Figura 5 - Coleta de lixo

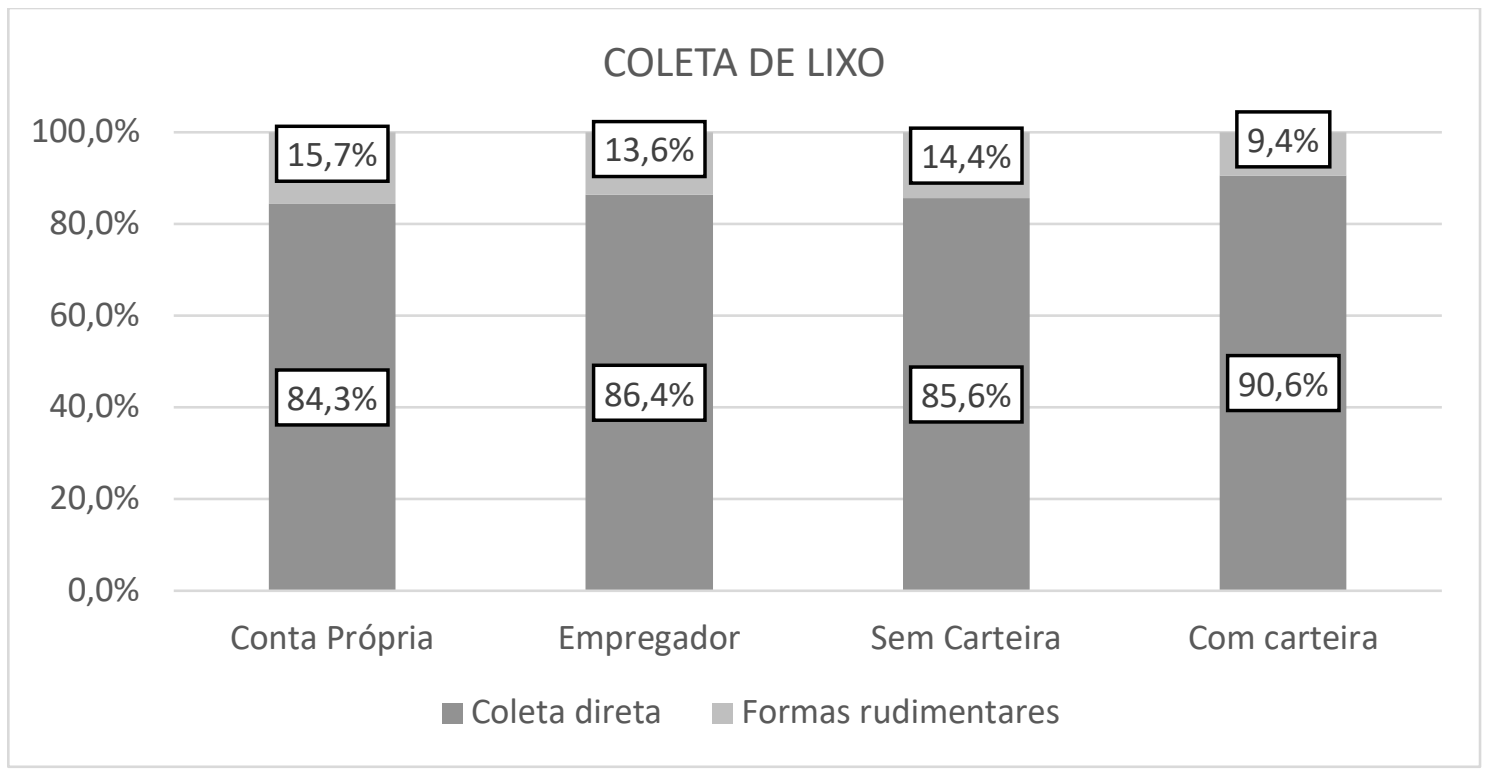

Fonte: elaborado pelos autores

DOI: $10.14211 /$ xi-egepe-118127 
beneficia de um medidor único, havendo pouca variação entre os perfis de trabalho. No entanto, os casos que usam formas rudimentares envolvem práticas como uso de medidor compartilhado, falta de medidor de eletricidade, óleo, querosene, gás ou vela.

Figura 6 - Eletricidade

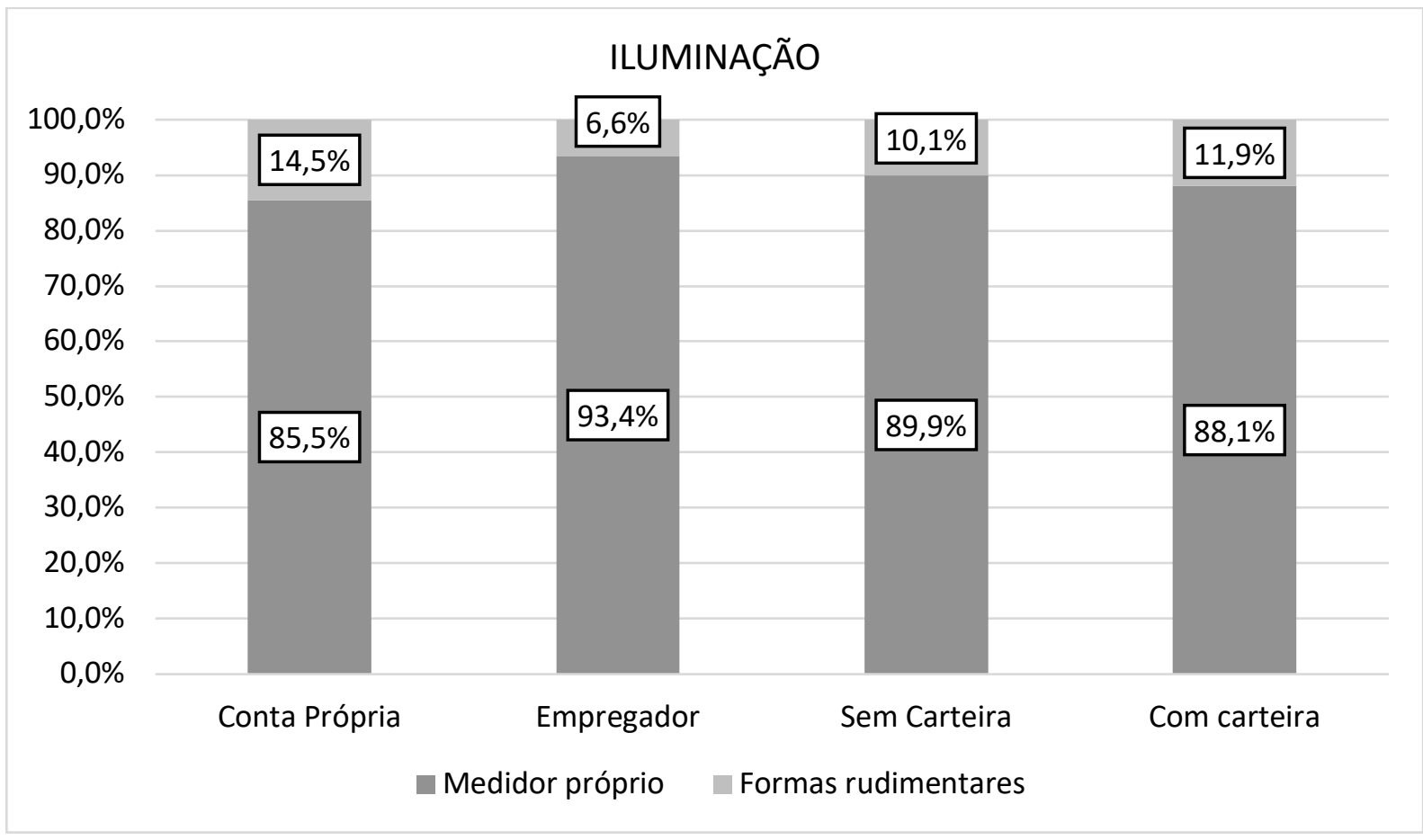

Fonte: elaborado pelos autores

Em relação ao calçamento, observa-se certa semelhança entre os grupos pesquisados. No entanto, ressalta-se uma proporção de pavimentação total levemente superior para os casos de trabalhadores assalariados.

Figura 7 - Calçamento

\section{CALÇAMENTO}

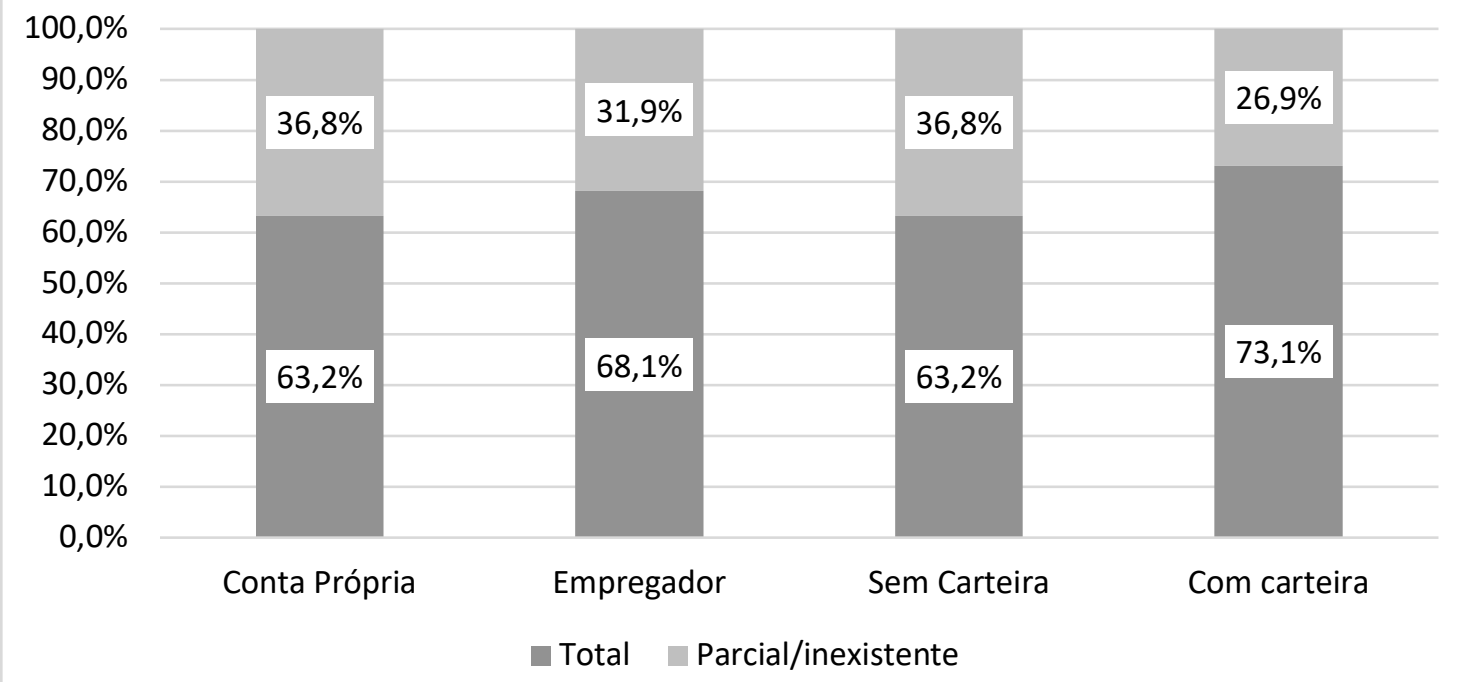


esgoto em detrimento de formas rudimentares, que envolvem vala a céu aberto ou descarte direto em rio, lago ou mar. Nota-se que, diferente dos demais, estes dados mostram uma piora relativa do trabalhador de carteira sobre os demais.

Figura 8 - Esgoto

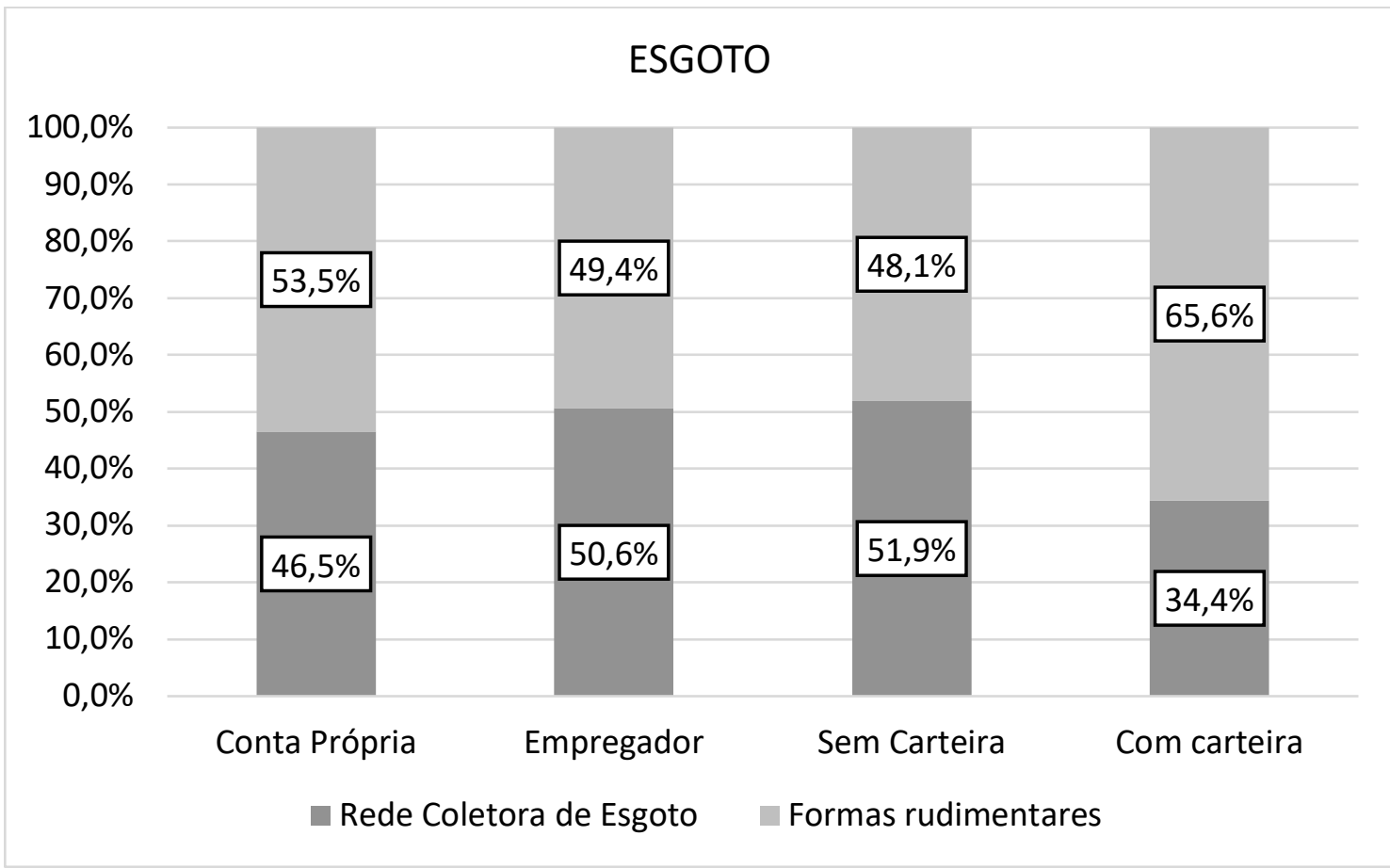

Fonte: elaborado pelos autores

Diante desses dados de infraestrutura, é possível perceber pelas proporções que de modo geral as condições habitacionais seguem um padrão relativamente próximo. Todavia, nesse caso, os empregados com carteira estão sob circunstâncias de menor qualidade.

Todas essas constatações também foram submetidas ao teste qui-quadrado. Em todos resultados, a estatística do teste foi elevada $p$-valor $<0,01$, indicando associação elevada entre os perfis de trabalho do público e as variáveis analisadas.

\section{Conclusões}

A presente pesquisa buscou descrever um perfil de empreendedores no contexto de pobreza. Nesse sentido, foi possível analisar variáveis demográficas de quatro diferentes públicos - trabalhadores por conta própria, trabalhadores sem carteira, trabalhadores com carteira e empregadores.

Com base nos dados demográficos, foi possível constatar baixa variabilidade em relação às questões sobre as condições habitacionais entre os grupos. No entanto, houve grande divergência sobre questões, como beneficiários do programa bolsa família e a renda mensal, nas quais os trabalhadores por conta própria encontram-se em desvantagem em relação aos demais grupos.

Essa pesquisa teve um foco exploratório, buscando compreender melhor esse grupo de empreendedores no Brasil. Uma contribuição importante do trabalho foi apresentar um eixo de possibilidades para a pesquisa em empreendedorismo, que é o uso de uma base de dados secundários ampla. 
concatenação de várias bases de dados disponibilizadas abertamente por instituições governamentais brasileiras, é possível associar dados sobre empreendedores em condições de pobreza com questões de infraestrutura, consumo e características de municípios, por exemplo.

A presente pesquisa se limitou a explorar de modo descritivo os dados sobre os empreendedores. Pesquisas futuras poderiam buscar compreender relações de causalidade entre variáveis, tanto para as previstas na base do cadastro único, como também para variáveis que possam estar em outras bases. Um exemplo interessante é usar a base de municípios para investigar como instituições podem influenciar as dinâmicas do trabalhador por conta própria. Ainda sobre propostas de novas investigações, ressaltase que a parcela de mulheres foi um número significativo entre os empreendedores com baixa renda. Isso sugere que mais estudos podem ser conduzidos para compreender as especificidades que circundam esse público.

\section{Referências}

BARROS, A. A.; PEREIRA, C. M. M. A. Empreendedorismo e Crescimento Econômico: uma Análise Empírica. Revista de Administração Contemporânea, v. 12, n. 4, p. 975-993, 2008.

BECK, T.; DEMIRGUC-KUNT, A.; LEVINE, R. SMEs, Growth, and Poverty: Cross-Country Evidence. Journal of Economic Growth, v. 10, p. 199-229, 2005.

BRUTON, G. D.; KETCHEN, J.; IRELAND, R. D. Journal of Business Venturing Entrepreneurship as a solution to poverty. Journal of Business Venturing, p. 1-7, 2013.

CUMMING, D.; JOHAN, S.; UZUEGBUNAM, I. An anatomy of entrepreneurial pursuits in relation to poverty. Entrepreneurship \& Regional Development, v. 00, n. 00, p. 1-20, 2019.

FIELDS, G. S. Self-employment and poverty in developing countries. IZE, n. March, p. 1-10, 2019.

GEORGE, G.; KOTHA, R.; PARIKH, P.; ALNUAIMI, T.; BAHAJ, A.S. Social structure, reasonable gain, and entrepreneurship in Africa. Strategic Management Journal, v. 37, n. 6, p. 1118-1131, 2016.

GINDLING, T. H.; NEWHOUSE, D. Self-Employment in the Developing World. World Development, v. 56, p. 313-331, 2014.

HOLZMANN, L. O Trabalhador por Conta Própria no Brasil. Revista Paranaense de Desenvolvimento, v. 34, n. 124, p. 119-137, 2013.

IBGE. Síntese de Indicadores Sociais Uma Análise das Condições de Vida da População Brasileira, 2019.

KOROSTELEVA, J.; STĘPIEŃ-BAIG, P. Climbing the poverty ladder: the role of entrepreneurship and gender in alleviating poverty in transition economies. Entrepreneurship \& Regional Development, v. 00, n. 00, p. 1-24, 2019.

KRASNIQI, B. A. Characteristics of self-employment: A refuge from unemployment or road to entrepreneurship. Small Enterprise Research, v. 21, n. 1, p. 33-53, 2014.

MANDELMAN, F. S.; MONTES-ROJAS, G. V. Is Self-employment and Microentrepreneurship a Desired Outcome. World Development, v. 37, n. 12, p. 1914-1925, 2009.

MOREIRA, R. F. C. Empreendedorismo e inclusão produtiva: uma análise de perfil do microempreendedor individual beneficiário do Programa Bolsa Família. Radar: tecnologia, produção e comércio exterior. 2013. 
entrepreneurship and economic development. Small Business Economics, v. 45, n. 4, p. $713-728,2015$.

NAUDÉ, W. Promoting Entrepreneurship in Developing Countries: Policy Challenges. United Nations University, 2010.

PLOTNIKOVA, M.; ROMERO, I.; MARTI, J. A. Process innovation in small businesses: the self-employed as entrepreneurs. Small Business Economics, n. 47, p. 939-954, 2016.

ROCHA, S. Pobreza no Brasil: afinal, de que se trata?. FGV Editora, 2003.

SANTIAGO, C. E. P.; VASCONCELOS, A. M. N. Do catador ao doutor: um retrato da informalidade do trabalhador por conta própria no Brasil. Nova Economia, v. 27, n. 2, p. 213-246, 2017.

SARKAR, S.; RUFÍN, C.; HAUGHTON, J. Inequality and entrepreneurial thresholds. Journal of Business Venturing, v. 33, n. 3, p. 278-295, 2018.

SEN, A. Desenvolvimento como liberdade. Editora Companhia das Letras, 2018.

SLADE, A.; ZIETSMA, C. The opportunity not taken : The occupational identity of entrepreneurs in contexts of poverty. Journal of Business Venturing, v. 33, n. 4, p. 416-437, 2018.

Smith, A. M., Galloway, L., Jackman, L., Danson, M., \& Whittam, G

SMITH, A. M., GALLOWAY, L., JACKMAN, L., DANSON, M., \& WHITTAM, G. Poverty, social exclusion and enterprise policy: A study of UK policies' effectiveness over 40 years. The International Journal of Entrepreneurship and Innovation, v. 20, n. 2, p. 107-118, 2019.

SUTTER, C.; BRUTON, G. D.; CHEN, J. Entrepreneurship as a solution to extreme poverty: A review and future research directions. Journal of Business Venturing, v. 34, n. 1, p. 197-214, 2018.

TAMVADA, J. P. Entrepreneurship and welfare. Small Business Economics, v. 34, p. 65-79, 2010.

VIVARELLI, M. Is entrepreneurship necessarily good? Microeconomic evidence from developed and developing countries. Industrial and Corporate Change, v. 22, n. 6, p. 1453-1495, 2013.

YANYA, M.; ABDUL-HAKIM, R.; ABDUL-RAZAK, N. A. Does entrepreneursship bring an equal society and alleviate poverty? Evidence from Thailand. Procedia - Social and Behavioral Sciences, v. 91, p. 331-340, 2013. 